\title{
Travel demand for metro in Ho Chi Minh City: A discrete choice experiment analysis
}

\author{
NGUYEN THANH SON \\ sonnguyenkth@gmail.com \\ NGUYEN DUY CHINH \\ duychinh@gmail.com
}

\section{ARTICLE INFO ABSTRACT}

Article history:

Received:

Jan., 16, 2017

Received in revised form:

May, 22, 2017

Accepted:

June, 30, 2017
By employing discrete choice experiment with face-to-face survey data of 135 local inhabitants in Ho Chi Minh City, this paper analyzes preference for the urban metro network transportation. The result reveals that seat availability, time, and cost reduction of the trip with metro robustly incite users to utilize this transportation service. Passengers of metro are willing to pay 0.606 and 4.106 thousand VND for one minute reduction of travel time and seat availability on the train cart, respectively. Furthermore, monetary welfare gained for a switch to metro is 64.3 thousand VND for each individual. Some implications regarding ticket prices and policy are also discussed.

Keywords:

Discrete choice

experiment

Urban transportation

mode

Metro travel demand

Ho Chi Minh City 


\section{Introduction}

Urban traffic congestion is one of the most frequently confronted issues in developing countries in Southeast Asia, especially in Vietnam. Owing to the inability of urban transportation infrastructure development to keep pace with the growing number of private vehicles, the congestion situation in major cities, namely Hanoi and Ho Chi Minh (HCMC), has been further aggravated in recent years. With the population of nearly 8 million in HCMC in 2013 (General Statistics Office of Vietnam, 2013), vast travel demand arises and accompanies a large number of motorbikes and cars. Reportedly, the volume of registered vehicles in HCMC witnessed a fivefold increase from 1.1 to 5.43 million in the period of 2000-2011 and is expected to rise by 2 million, reaching 7.43 million by the end of 2015 (Department of Transport HCMC, 2016). Coupled with around 1 million motorbikes immigrating from other provinces, the ratio of motorcycle per person could be exorbitant. However, the city space allocated for transportation, in comparison with that of other cities worldwide, in average (20-25\%), is approximately $7.8 \%$ lower. On the other hand, the public bus service, which is initially anticipated to alleviate the transportation burden of the city, has been unsuccessful. To be specific, barely $5 \%$ of the city population utilizes this service and most citizens choose motorbike as their main transportation mode $(\mathrm{Vu} \& \mathrm{Do}$, 2013).

Lately, the Ho Chi Minh City Metro project, which was proposed in 2002, has attracted attention of the local government as it is expected to resolve the traffic congestion issue. The project comprises six lines and will be implemented based on Build-Operate-Transfer (BOT) and Public Private Partnerships (PPP). Currently, two first metro lines have been constructed since 2009 and will be in operation in 2020. The posed question is, under these circumstances, whether citizens will make use of the metro in substitution for other transportation means or continue using private vehicles. This requires determinants of transportation choice and probabilities of usage to be respectively examined and estimated. Furthermore, to assist in policy making processes, welfare changes for metro use and attribute improvements will also be analyzed. The results of this study are expected to be useful to policy makers, urban planners, and administrators of the railway project in terms of demand forecast, prices set for the metro service, and public transportation planned for the city in the future.

This study applies discrete choice experiment (DCE) method with data of individuals in HCMC to explore the choice preference to metro transport. Justification for the application of DCE method could be made by the following points. First, DCE is a commonly exercised method in demand estimation or valuation of goods and services, especially when they are hypothetical or not yet accessible (Lancsar \& Louviere, 2008), which is the case of metro network in HCMC. Second, given the difficulty in sampling involved in large 
populations such as HCMC, DCE could prevail as a fitting method. To further elaborate, while non-experimental methods, binary analysis for instance, could collect information relating to one actual choice for each observation only, DCE, on the other hand, allows for choice repetition for each respondent. This effectively produces larger dataset and robust estimates thanks to variations in attribute levels (Bateman et al., 2002). Third, DCE has the ability to draw forth monetary benefit (willingness to pay) (WTP) for individual characteristics and the hypothetical scenario as a whole, which could potentially be used as inputs in project appraisals and policy making process (McIntosh, 2006).

\section{Literature review}

DCE method has its theoretical foundations in the attribute theory of consumers (Lancaster, 1966) and random utility theory. While the former emphasizes the importance of attributes of commodities in utility acquisition, the latter, on which the analytical framework of DCE is based, is derived from the psychological study of Thurstone (1927), which argued that formulation of an individual's choice is a result of a process in which random components are associated with alternatives, given that the decision maker has full realization of the choice. If the actual stimuli in this theory were replaced with satisfaction, or in other words, utility, then the resulting choice could be explained by an economic choice model where an individual will choose the alternative producing the highest utility level (McFadden, 2001).

Marschak (1959) first introduced Thurstone (1927)'s concepts into economics by proposing random utility maximization theory in which an individual's utility is maximized using choice probabilities. The theory had been developed into theoretical framework by Manski (1977), before extended into analytical framework in many studies (McFadden, 1980; McFadden, 1986; McFadden \& Train, 2000). These frameworks have been widely adopted in many fields of research, ranging from medicine and economics to transportation, and diversely tailored by incorporating different econometric techniques, including categorical regression models and structural equation modelling (Rungie et al., 2011).

In the field of transportation research, despite the vast amount of empirical literature, studies concerning travel mode choice considerably vary due to a wide assortment of different choice set designs, econometric techniques, and data employment. Several common experiment designs are orthogonal design, D-efficient design, and random design. Econometricwise, multinomial logit, nested logit, mixed logit, heteroskedastic extreme value, and multinomial probit are popular models (Kjær, 2005).

Given characteristics of the decision maker only, multinomial logit is the dominant model in the literature. However, several earlier studies are different in terms of experiment design. For example, while Brewer and Hensher (2000), Leitham et al. (2000), and Garrod et al. (2002) utilized orthogonal design with unlabeled 
transportation alternatives and randomly designed task assignment, Wang et al. (2000), Henser and Prioni (2002), Zhang et al. (2004) employed orthogonal design in conjunction with blocked attribute design for choice sets. Other less common designs are typically adopted in the study of Cantillo and de Dios Ortúzar (2005) with D-efficient design and Hollander (2006) with random design.

Nested logit model, in comparison with multinomial logit, allows for grouping of similar alternatives in choice sets, typically employed in studies related to public transportation and private vehicle choice. However, like studies that utilized multinomial logit technique, different designs were employed. Hensher and King (2001) applied orthogonal design with labeled alternatives, whereas in other studies (e.g., Bhat \& Castelar, 2002; Jovicic \& Hansen, 2003; Cherchi \& de Dios Ortúzar, 2006; Espino et al., 2006) revealed preference data were combined with stated preference data to alleviate technical limitations occurring only when one type of data is used.

To relax some statistical assumptions of the previous models and enable taste variations of individuals, mixed logit model was developed. Similar to other studies, many experimental designs were applied. Several studies which used unlabeled orthogonal design include Hensher (2001), Hensher and Greene (2003), Tseng and Verhoef (2008), McDonell et al. (2009), Sener et al. (2009), and Rouwendal et al. (2010). D-efficient technique was employed in Greene et al. (2006), Hensher and Rose (2007), Puckett et al. (2007), Hensher (2008a, 2008b), Hensher et al. (2008), Hensher et al.
(2009), Hess and Rose (2009), and Puckett and Hensher (2009). A typical study with random design in this category is Train and Wilson (2008).

Other less common econometric models such as ordered logit, ordered probit, and rank ordered logit were applied in studies of Wang, Hensher and Ton (2002), de Palma and Picard (2005), Ahern and Tapley (2008), and Beuthe and Bouffioux (2008).

In the scope of HCMC, there are also several studies concerning urban transportation mode choice. The earliest study of Nguyen (1999), for instance, employed a multinomial choice model of private vehicle to calculate commuter values of time, which would be subsequently used to make suggestion for congestion toll. The model regards trips as units of analysis, thus it is capable of taking into account both modes of specific and socio-economic factors. However, its specification is relatively simple, and public transport option is left out in this study.

Later studies of mode choice in HCMC began to consider this factor into models. Ho and Yamamoto (2011) established a generalized nested logit model of private vehicle choice and incorporated public bus availability as independent variables. Ten combinations of household vehicle ownership were used to form a single dependent variable in this study. The results pointed out that, apart from income, perceived bus-related characteristics such as coverage and convenience greatly influenced households' behavior to own multiple private vehicles. 
Tuong (2014) examined determinants of commuting mode choice in HCMC at the descriptive level using a small sample of participants. Although the applied technique was not rigorous, the results revealed several interesting insights. First, cost and time saving are two main factors urging inhabitants to commute either by bus or motorbike, rather than social or environmental concerns. Second, perceived instrumental value of public bus is not highly valued. Therefore, a more developed and convenient public transport system is essential to the city in the future.

Similar to Tuong (2014) in terms of research objectives, Nguyen et al. (2015) applied a conventional logit model with data of individuals in HCMC. However, only two alternatives, public and private transportation, were treated as dependent variable. Sensitivity analysis was also conducted in the logistic expression with respect to congestion and parking cost to find out how a change in travel cost would induce people to utilize public transport. Generally, the results of this study highlight the importance of cost and time to public transportation behavior.

These studies, although diverse in terms of technique employment, do expose several shortcomings. First, they are unable to incorporate choice-specific variables which are variant across both alternatives and choosers. Second, welfare gained (or lost) when inhabitants switch a different mode of transport has not properly analyzed. These will be addressed in this study.

\section{Experiment design, methods, and data}

In urban areas with complex networks of travel mode alternatives, the transportation behavior modelling of travelers could be a difficult and complicated task. Often, for various reasons, urban commuters utilize different modes of transport for their purposes. However, it would be impossible for a choice model to accommodate either non-mutually exclusive or infinite choices to account for this fact (Train, 2009). In addition, attributes of preference for each travel alternative could be different. For example, the parking cost attribute cannot be present considering public transportation, or metro, thanks to its high level of mechanization, virtually could not cause any delay in delivering the transportation service. Therefore, generalization of urban transportation is required before an experiment design is attempted. Arentze and Molin (2013) classified the urban transportation into three main types and disaggregated them into phases with associated attributes. The detailed categorization is shown in the figure below: 
Motorbike and car transportation:

\begin{tabular}{|c|c|c|}
\hline Main phase & & Last phase \\
\hline Travel time & & Walking time \\
\hline Travel cost & & Parking cost \\
\hline Delayability & & Parking time \\
\hline Taxi service & & \\
\hline Main phase & & Last phase \\
\hline Travel time & & Walking time \\
\hline Travel cost & & Parking cost \\
\hline Waiting time & & Parking time \\
\hline Delayability & & \\
\hline Public transp & & \\
\hline First phase & Main phase & Third phase \\
\hline Travel time & Travel time & Travel time \\
\hline Travel mode & Travel mode & Travel mode \\
\hline Waiting time & Waiting time & Waiting time \\
\hline Parking cost & Transition time & \\
\hline & Seat availability & \\
\hline & Station infrastructure & \\
\hline & Delayability & \\
\hline
\end{tabular}

Figure 1. Attributes of urban transportation

Source: adapted from Arentze and Molin (2013)

Generally, from the perspective of an individual, a particular mode of transport in the urban area, whether it is public, private, or competitively provided, could be characterized by four primary attributes: time, cost, seat availability, and infrastructure quality. Time could be measured by travelling time on the vehicle plus transiting time and/or any variations caused by traffic delays, waiting periods, or parking. Cost includes petrol cost, parking cost and depreciation for private vehicle, transiting cost, or ticket fee for public transporting. For seat availability and infrastructure, this study excludes the latter since it would be difficult and biased for an individual to rate the quality of the public transport facilities, given that the bus service is poorly utilized and the scenario of the existence of a metro system is relatively 
hypothetical. In addition, incorporation of subjective valuation is not recommended in conditional logit DCE since it may raise response errors (Li \& Mattsson, 1995).

Given the aforementioned notion, the experiment design for this study is as follows. First, the survey process consists of two stages whose data feature preference data and stated preference data, respectively. The combined use of two types of data is intended to limit the collinearity problem, which often arises from strong correlation of attributes of alternatives (Adamowicz et al., 1994). The initial stage of the survey aims to collect information relating to travel purposes and their corresponding attribute data of the utilized modes of transport associated with travel purposes, including total time, seat availability, and total cost. Then, a scenario of the metro network in HCMC, which includes specific metro characteristics, images of train carts, and a detailed map of metro lines, is elicited. Consequently, in the second stage, respondents are required to make a choice of transportation between a mode with highest utilization frequency and the proposed metro scenario. In particular, ten consecutive choice sets are given with different metro prices and seat availability options. Respondents' socio-economic characteristics are also collected at the end of the survey.

Second, regarding choice set building, random design will be employed as orthogonal and D-efficient design are not appropriate when attributes and corresponding levels are not abundant. To be specific, a focus group discussion was held to assemble cost estimates for current public transportation methods in HCMC. The results show that if the travel demand of an average income individual in HCMC could be fully satisfied by public transportation, it would cost that person roughly $1,000 \mathrm{VND}$ per kilometer travelled. Therefore, in combination with two seat availability options, ten choice sets are constructed with prices ranging from 300 to $1,250 \mathrm{VND}$ and five intervals of 200, 250, 250, 250, and 250 VND. The table below illustrates a sample choice set in the second stage.

\section{Table 1}

Sample choice set in the survey

Assuming you are offered two transportation choices for your most frequent purpose of travel, which is going to work. Two options are your current mode, which is motorbike, and metro. The metro would cost you $300 \mathrm{VND}$ per kilometer and there is NO seat availability. What would you choose?

\begin{tabular}{lll}
\hline & Your current mode: $\underline{\text { motorbike }}$ & Metro \\
\hline Total travel time & $\underline{30}$ minutes & $\underline{10}$ minutes \\
Seat availability & Yes & No \\
Travel cost & $\underline{9,000}$ VND & $\underline{15,000}$ VND \\
Parking cost & $\underline{3,000}$ VND & 0 VND \\
\hline
\end{tabular}




\section{Choice of} transportation

\section{$\mathrm{X}$}

Note: In the actual survey, underlined information would be filled or calculated based on the first stage of the survey. To be specific, information in the 'your current mode' column is transferred from the first stage. In the metro column, 'Total travel time' is calculated by dividing the reported distance of the travel purpose by the velocity specification of train cart, and 'Total travel cost' is calculated by multiplying the distance by given metro price.

To establish the analytical framework in this study, the utility framework will be applied to accommodate two categories, which are modes of transport characteristics and individual characteristics (Yang et al., 2009). These two categories will be subsequently analyzed with the econometric model of conditional logit to determine their impacts on inhabitants' choice of mode of transport. Attributes of modes include total transporting time, total transportation cost, and seat availability on the mode.

Within the economic framework, when facing with $J$ mutually exclusive alternatives, an individual will make decision on the utility maximization basis. In other words, he or she will choose the alternative which yields the highest utility compared to the rest. Thus, when two alternatives are considered, the probability of an $n$ individual to choose an $i$ transportation mode over a $j$ mode is:

$$
P_{n i}=\operatorname{Pr}\left(U_{n i}>U_{n j}\right), \forall j \neq i
$$

where $U$ is the utility function of an individual when he or she chooses an alternative. The random utility maximization theory stated that $U$ consists of two parts, which are deterministic component, $V$, and an alternative-invariant unobserved random component, $\varepsilon$. Thus, the probability function can now be rewritten as:

$$
\begin{gathered}
P_{n i}=\operatorname{Pr}\left(V_{n i}+\varepsilon_{n i}>V_{n j}+\varepsilon_{n j}\right), \forall j \neq i \\
=\operatorname{Pr}\left(\varepsilon_{n j}-\varepsilon_{n i}<V_{n i}-V_{n j}\right), \forall j \neq i
\end{gathered}
$$

Assuming the deterministic part is a linear function of coefficients, $\beta$, and attributes transportation mode of choice, $S_{i}$. The indirect utility function is rewritten as:

$$
V_{n i}=A S C_{i}+\beta S_{i}, \forall j \neq i
$$

where $\quad A S C_{i} \quad$ (Alternative-Specific Constant) represents effects unrelated to transportation mode attributes to the indirect utility of the decision maker. $S_{i}$ is assumed to vary by alternative and $\beta$ is constant for individuals, but differs for each transportation mode.

In the context of this study, two conditional logit models will be estimated. The first standard model includes alternative-specific variables and alternative-specific constants for different modes of transport. Assuming random components follow Gumbel distribution, the probability that the $n$ agent will choose the $i$ alternative is:

$$
P_{n i}=\frac{\exp \left(V_{n i}\right)}{\sum_{j=1}^{J} \exp \left(V_{n j}\right)}, \forall j \neq i
$$


Since the standard model is not capable of including person-specific attributes as they do not vary across choices (Long \& Freese, 2006), the second model, the general conditional logit model, will incorporate additional person-specific variables. Therefore, the probability function in this model will be:

$$
P_{n i}=\frac{\exp \left(V_{n i}+\beta_{n} x_{i}\right)}{\sum_{j=1}^{J} \exp \left(V_{n j}+\beta_{n} x_{j}\right)}, \forall j \neq i
$$

where $x_{i}$ is the vector comprising personspecific variables. In estimation of this model, a dummy variable is created and equal to 1 if the observation is metro. The dummy will be interacted with personspecific variables in the study to disallow it to vary across alternatives. Some specifications of variables used are given in the table below:

\section{Table 2}

Variable description

\begin{tabular}{lll}
\hline Variable & Description & Expected sign \\
\hline Dependent variable & \\
Choice & $\begin{array}{l}\text { Respondents' choice of transportation mode in long } \\
\text { data format }\end{array}$ & \\
&
\end{tabular}

Alternative-specific variable

Total time Numerical data indicating total time spent on the corresponding choice (in minute)

Total cost Numerical data indicating total cost spent for the trip (including parking cost) in 1,000 VND

Seat availability A dummy which equals to 1 if the alternative of choice has seats available, 0 otherwise

Individual-specific variable

Gender Equals 1 if the respondent is male, 0 otherwise

Age Numerical data

Schooling years Numerical data

Income Numerical data (in thousand VND)

Motorbike ownership Equals 1 if the respondent owns at least one motorbike, 0 otherwise

The conditional logit model also allows for calculation of marginal rates of substitution 
between attributes, which, in turn, is used to produce willingness to pay (WTP) for a change in utility, or, in other words, a change in an attribute. To be specific, the gained (or lost) welfare through a change in an $k$ attribute of a transportation mode is calculated as follows:

$$
W T P_{k}=-\frac{\beta_{k}}{\beta_{\text {totalcost }}}
$$

For the conditional logit model, estimated coefficients are asymptotically normally distributed. Therefore, a confidence interval for WTP can be constructed (Hole, 2007).

The individual data are collected using face-to-face direct survey. Non-probabilistic convenience method is employed. To be specific, five districts on which $1^{\text {st }}$ and $2^{\text {nd }}$ metro lines are expected to be constructed are selected to survey. The sample data consist of 135 individuals, with 27 individuals for each district. In each district, two survey sessions that were conducted comprise a morning session, which took place in a university located in that district, and an evening session, in a supermarket. Only respondents aged 18 or older were selected, and it took approximately 20 minutes to fully survey a respondent.

\section{Results and discussion}

The standard conditional logit model is initially run with three characteristics of transportation modes. Then, WTP and its corresponding confidence interval for eachattribute are calculated. The estimates for the metro choice are presented in the table below:

\section{Table 3}

Utility estimates for metro choice of the standard conditional logit model

\begin{tabular}{lccccccc}
\hline \multicolumn{1}{c}{ Variable } & Coefficient & S.D. & P-value & Odd-ratio & WTP & $\begin{array}{c}\text { Lower } \\
\text { WTP }\end{array}$ & $\begin{array}{c}\text { Upper } \\
\text { WTP }\end{array}$ \\
\hline Total cost & -0.076 & 0.012 & 0.000 & 0.926 & & & \\
Total time & -0.069 & 0.013 & 0.000 & 0.933 & -0.904 & -1.432 & -0.542 \\
Seat availability & 0.296 & 0.113 & 0.009 & 1.344 & 3.869 & 0.955 & 7.590 \\
ASC & -0.368 & 0.200 & 0.066 & 0.692 & -4.815 & -4.011 & -3.197 \\
\hline Log-likelihood & -884.544 & & & & & & \\
LR Chi2 (4) & 151.06 & & & & & & \\
Adj. R-squared & 0.075 & & & & & &
\end{tabular}




\begin{tabular}{|c|c|c|c|c|c|c|c|}
\hline Variable & Coefficient & S.D. & P-value & Odd-ratio & WTP & $\begin{array}{c}\text { Lower } \\
\text { WTP }\end{array}$ & $\begin{array}{l}\text { Upper } \\
\text { WTP }\end{array}$ \\
\hline $\mathrm{BIC}$ & - 7932.691 & & & & & & \\
\hline $\mathrm{N}$ & 2760 & & & & & & \\
\hline Sample size & 135 & & & & & & \\
\hline
\end{tabular}

Note: WTP is measured in thousand VND, and WTP confidence intervals are inferred using KrinskyRobb bootstrapping method.

At first glance, all the signs of the variables in the standard model are consistent with the expectation. While negative signs of the two variables cost and time signify the lessening probability of choosing metro option when opportunity costs of the service increase, seat availability improvement tends to stimulate people to use the hypothetical metro option. Furthermore, the statistical insignificance of the ASC implies that there is no disparity in preference when individuals are faced with a choice between the existing mode and metro, assuming that their paired attributes are identical. In other words, when only the characteristics of modes of transport are taken into account, inhabitants in HCMC do not prefer to switch to metro.

The WTP calculations show that with a reduction of one minute in travelling, willingness to pay, or monetary welfare, of an individual will rise by 0.904 thousand VND. Welfare is also increased by 3.869 thousand VND by ensuring seat availability in the metro during the travel period. The coefficient of ASC is not statistically significant in this model. Thus, the model is unable to calculate reliable WTP estimate for a switch to metro from other transport alternatives.

To further examine the impacts of individual characteristics on the choice of metro, the general conditional logit regression is conducted by having personspecific attributes interacted with ASC dummies. The motorbike ownership dummy is excluded from the model since a large proportion of the sample (94\%) owns at least one private vehicle, which makes the loglikelihood function fail to produce valid estimates. The results are presented in the table below: 


\section{Table 4}

Utility estimates for metro choice of the general conditional logit model

\begin{tabular}{|c|c|c|c|c|c|c|c|}
\hline Variables & Coefficients & S.D. & P-value & Odd-ratio & WTP & $\begin{array}{l}\text { Lower } \\
\text { WTP }\end{array}$ & $\begin{array}{l}\text { Upper } \\
\text { WTP }\end{array}$ \\
\hline \multicolumn{8}{|c|}{ Alternative-specific } \\
\hline Total cost & -0.079 & 0.013 & 0.000 & 0.924 & & & \\
\hline Total time & -0.048 & 0.013 & 0.000 & 0.953 & -0.606 & -1.071 & -0.268 \\
\hline Seat availability & 0.330 & 0.118 & 0.005 & 1.391 & 4.160 & 1.217 & 7.995 \\
\hline ASC & 5.105 & 0.698 & 0.000 & 164.87 & 64.360 & 42.196 & 99.560 \\
\hline \multicolumn{8}{|c|}{ Individual-specific } \\
\hline ASC $\times$ age & -0.290 & 0.035 & 0.000 & 0.748 & & & \\
\hline ASC $\times$ male & -0.113 & 0.122 & 0.354 & 0.893 & & & \\
\hline ASC $\times$ income & 0.072 & 0.028 & 0.010 & 1.074 & & & \\
\hline $\begin{array}{l}\text { ASC } \\
\text { schooling }\end{array}$ & 0.121 & 0.058 & 0.037 & 1.129 & & & \\
\hline Log-likelihood & -822.689 & & & & & & \\
\hline LR Chi2 (4) & 274.781 & & & & & & \\
\hline Adj. R-squared & 0.135 & & & & & & \\
\hline AIC & 1.231 & & & & & & \\
\hline $\mathrm{BIC}$ & -8027.570 & & & & & & \\
\hline $\mathrm{N}$ & 2760 & & & & & & \\
\hline Sample size & 135 & & & & & & \\
\hline
\end{tabular}

Note: WTP is measured in thousand VND, and WTP confidence intervals are inferred using KrinskyRobb bootstrapping method.

Similar to the standard model, the individual-specifics enter the model. In general one yields statistically significant comparison with the previous model, this alternative-specific estimates whose signs change of ASC could be interpreted as adhere to initial expectations, except for ASC, which is dramatically altered in terms of both magnitude and significance when follows. First, there is a difference in preference when an individual chooses between existing vehicles and metro, 
holding their paired attributes identical. In other words, metro is preferred to other alternatives. Second, the switching behavior may be attributed to demographic characteristics of individuals, rather than attributes of modes of transport.

Demographic variables show significant impacts on the mode choice, except for gender. To be specific, as people get wealthier, or attain more schooling years, they are more likely to use the metro service. While the former is empirically advocated in most studies, there is no existing theoretical explanation to justify the latter. However, one possible reason is that with higher education level, customers become more aware of the benefits that metro may bring, motivating them to use it when the system is actually implemented. Gender, on the other hand, has no influence on the mode choice, implying that there is no difference in the preference experienced between male and female.

WTP estimates for total time and total cost in the general model are different from those of the standard model due to the changes in coefficients. In the general model, welfare will increase by 0.604 thousand VND for a reduction of one minute of metro transportation. With ensured seat availability on metro, welfare could rise by approximately 4.1 thousand VND. Additionally, an individual is willing to pay 64.3 thousand VND to switch to metro from another mode implying that welfare of an individual increases by 64.3 thousand VND when metro is chosen to be utilized. This amount stems from the reduction of travel time when a particular trip is experienced using metro instead of other modes.

In terms of model fitness, the general model is more well suited to explain the behavior of the sample than the standard model since Log-likelihood, Akaike Information Criteria (AIC), and Bayesian Information Criteria (BIC) of the general model are higher than those of the standard one. In comparing the two models with different combinations of interaction terms, the general model still outperform the other in terms of AIC and BIC.

Following the econometric results, percentage of people willing to switch to metro and probabilities of choosing metro as the main mode of transport will be calculated from the sample data and the general conditional logit model, respectively. First, from the stated preference sample data, the number of people who would opt for a switch at different ticket prices is shown below: 


\section{Table 5}

Percentage of respondents who are willing to switch to the metro option

\begin{tabular}{lccccc}
\hline Ticket price (VND per kilometer) & 300 & 500 & 750 & 1000 & 1250 \\
Number of respondents switching & 96 & 93 & 91 & 81 & 73 \\
Percentage & $71 \%$ & $69 \%$ & $67 \%$ & $60 \%$ & $54 \%$ \\
\hline
\end{tabular}

Apart from that, the probabilities of the sample individuals choosing metro are calculated using the choice probability function from the general model:

$$
\operatorname{Pr}(\text { metro })_{n}=\frac{\exp \left(\beta_{\text {time }} \text { totaltime }+\beta_{\text {seat }} \text { seat }+\beta_{\text {metro }} \text { totalcost }+\alpha^{\prime} x_{n}\right)}{\sum_{j=1}^{J} \exp \left(\beta^{\prime} S_{i}+\alpha^{\prime} x_{n}\right)}
$$

where $\alpha^{\prime}$ and $\beta^{\prime}$ are vectors of metro as the main mode of transport. For coefficients of interactions terms and each price level and seat availability option, coefficients of mode characteristics a sample-averaged probability will be variables respectively. $\operatorname{Pr}(\text { metro })_{n}$ is the estimated accordingly. The results are probability that an $n$ individual will choose plotted in the graph below.

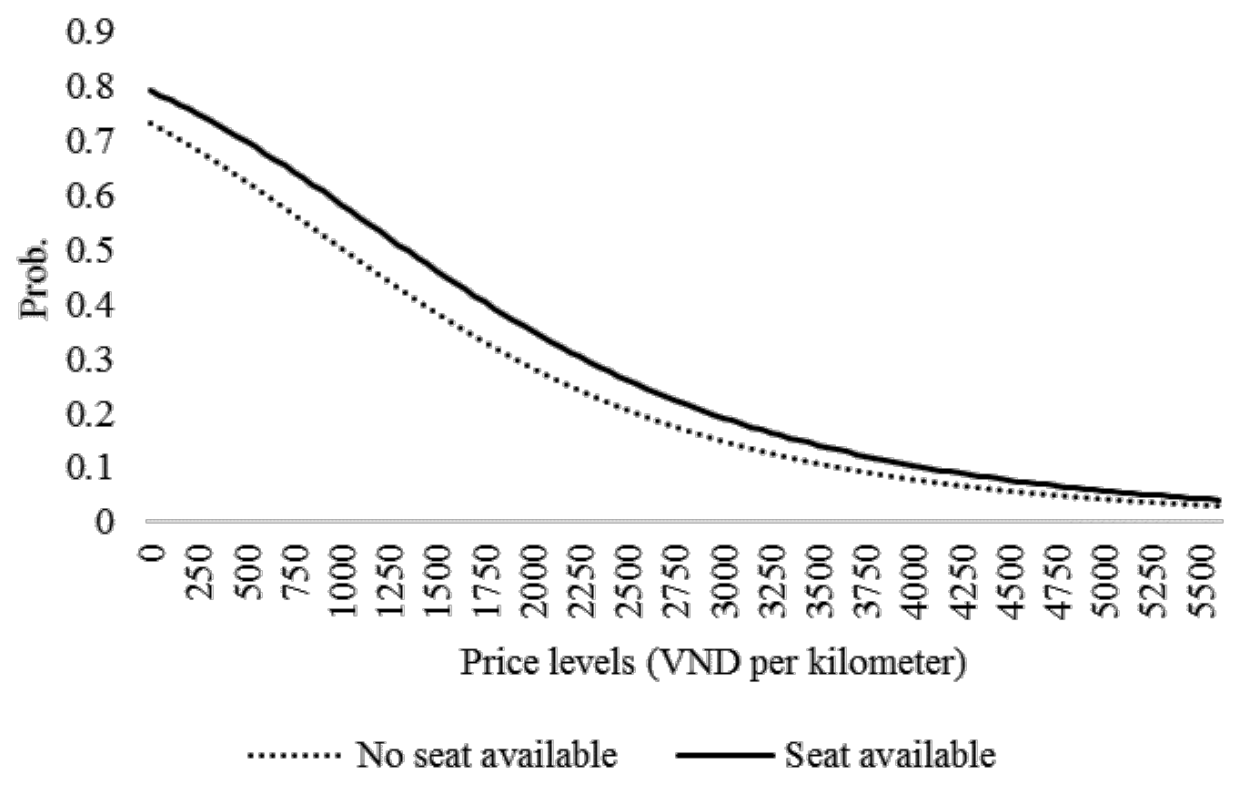

Figure 2. Predicted probabilities of metro utilization 


\section{Conclusion and policy implications}

By modelling passengers' choice of transportation in HCMC, this study finds out that, under the perspective of a passenger, the probability of utilizing metro as the main mean of transport is significantly influenced by its attributes, especially cost. Comparing to other transports, the preference to metro is indistinguishable when the demographic characteristics of passengers are absent. If they are not, metro is statistically favored, and in turn, giving rise to extra welfare as people switch to it.

Several shortcomings are recognized. First, owing to the subjective nature and technical difficulties, the study is unable to include a proper measurement for flexibility of transport means and availability of transiting facility for metro. Second, although the survey was administrated in a way that could limit the possibility of including informants who are not willing to use metro in the future, a sample selection bias may occur since the data sampling is non-random. Based on the research results, several implications could be drawn as follows.

First, the metro service, apart from its main purposes of reducing travelling time of urban inhabitants to a certain extent and relieving congestion, needs to be reasonably priced. According to the research findings, the ticket price must be lower than 1,350 VND per kilometer in order to incite $50 \%$ of users to switch to metro, at least. In terms of revenue maximization, further calculation from the choice probabilities reveals that at the price of approximately $2,250 \mathrm{VND}$ per kilometer, local authorities could earn the highest possible revenue. Although this price level comes with tradeoffs in the rate of metro users and customers' welfare, the government should consider this option temporary when the payback period of the project is of higher priority. Furthermore, at lower fee levels, by improving seat availability on train carts, additional users could be motivated to decide on the service. However, this measure loses its effectiveness in terms of attracting new users as the price goes up.

Second, given the diversity of transportation demand and high flexibility requirement of urban commuters, metro transportation is expected to be under-utilized by private vehicle owners in its early phase of implementation. However, upon completion of all six lines, coupling with developments of metro transiting facilities, urban transportation using metro could be easier and more convenient. The econometric results have pointed out that with a higher cost of a means of transport, users tend to resort to other modes with less expensive costs. Therefore, when the metro system fully develops and the service is able to satisfy most passengers in terms of both quality and quantity, local authorities could consider imposing policies to discourage private vehicle transportation by increasing its costs. These measures could eventually alter behavior of traditional citizens in $\mathrm{HCMC}$ to a metro-oriented moving habit.

Finally, the service should primarily aim to customers who are young, well educated, and possess a sustainable source of income. Since these people do not fall into preferential 
groups, which are ticket-exempted, and are willing to afford a higher cost, compared to that of other transportation alternatives, in order to be offset with shorter trips and improved service quality such as assured seat availability. Furthermore, they are more inclined to adopt modern technologies and are increasingly aware of the metro benefits. Evidently, the results show that people are willing to spend 606 VND for a reduction of one minute of travelling. This implication is further reinforced by the fact that not everyone prefers metro, even if its price becomes cheaper, as demonstrated by opposing significance of the two ASCs in both the models

\section{References}

Adamowicz, W., Louviere, J., \& Williams, M. (1994). Combining revealed and stated preference methods for valuing environmental amenities. Journal of Environmental Economics and Management, 26(3), 271-292.

Ahern, A. A., \& Tapley, N. (2008). The use of stated preference techniques to model modal choices on interurban trips in Ireland. Transportation Research Part A: Policy and Practice, 42(1), 1527.

Arentze, T. A., \& Molin, E. J. (2013). Travelers' preferences in multimodal networks: Design and results of a comprehensive series of choice experiments. Transportation Research Part A: Policy and Practice, 58, 15-28.

Bateman, I. J., Carson, R. T., Day, B., Hanemann, M., Hanley, N., Hett, T., ... \& Loomes, G. (2002). Economic valuation with stated preference techniques: A manual. Edward Elgar Pub.

Beuthe, M., \& Bouffioux, C. (2008). Analysing qualitative attributes of freight transport from stated orders of preference experiment. Journal of Transport Economics and Policy, 42(1), 105-128.

Bhat, C. R., \& Castelar, S. (2002). A unified mixed logit framework for modeling revealed and stated preferences: Formulation and application to congestion pricing analysis in the San Francisco Bay area. Transportation Research Part B: Methodological, 36(7), 593-616.

Brewer, A. M., \& Hensher, D. A. (2000). Distributed work and travel behaviour: The dynamics of interactive agency choices between employers and employees. Transportation, 27(1), 117-148.

Cantillo, V., \& de Dios Ortúzar, J. (2005). A semi-compensatory discrete choice model with explicit attribute thresholds of perception. Transportation Research Part B: Methodological, 39(7), 641657.

Cherchi, E., \& de Dios Ortúzar, J. (2006). On fitting mode specific constants in the presence of new options in RP/SP models. Transportation Research Part A: Policy and Practice, 40(1), 1-18.

de Palma, A., \& Picard, N. (2005). Route choice decision under travel time uncertainty. Transportation Research Part A: Policy and Practice, 39(4), 295-324.

Espino, R., Román, C., \& de Ortúzar, J. D. (2006). Analysing demand for suburban trips: A mixed 
RP/SP model with latent variables and interaction effects. Transportation, 33(3), 241-261.

Garrod, G. D., Scarpa, R., \& Willis, K. G. (2002). Estimating the benefits of traffic calming on through routes: A choice experiment approach. Journal of Transport Economics and Policy (JTEP), 36(2), 211-231.

General Statistics Office of Vietnam. (2013). Report on population variations and family planning survey. Hanoi, Vietnam.

Greene, W. H., Hensher, D. A., \& Rose, J. (2006). Accounting for heterogeneity in the variance of unobserved effects in mixed logit models. Transportation Research Part B: Methodological, 40(1), 75-92.

Hensher, D. A. (2001). Measurement of the valuation of travel time savings. Journal of Transport Economics and Policy, 35(1), 71-98.

Hensher, D. A. (2008a). Influence of vehicle occupancy on the valuation of car driver's travel time savings: Identifying important behavioural segments. Transportation Research Part A: Policy and Practice, 42(1), 67-76.

Hensher, D. A. (2008b). Joint estimation of process and outcome in choice experiments and implications for willingness to pay. Journal of Transport Economics and Policy (JTEP), 42(2), 297-322.

Hensher, D. A., \& Greene, W. H. (2003). The mixed logit model: The state of practice. Transportation, 30(2), 133-176.

Hensher, D. A., \& King, J. (2001). Parking demand and responsiveness to supply, pricing and location in the Sydney central business district. Transportation Research Part A: Policy and Practice, 35(3), 177-196.

Hensher, D. A., \& Prioni, P. (2002). A service quality index for area-wide contract performance assessment. Journal of Transport Economics and Policy, 36(1), 93-113.

Hensher, D. A., \& Rose, J. M. (2007). Development of commuter and non-commuter mode choice models for the assessment of new public transport infrastructure projects: A case study. Transportation Research Part A: Policy and Practice, 41(5), 428-443.

Hensher, D. A., Rose, J. M., \& Black, I. (2008). Interactive agency choice in automobile purchase decisions: The role of negotiation in determining equilibrium choice outcomes. Journal of Transport Economics and Policy, 42(2), 269-296.

Hensher, D. A., Rose, J. M., de Dios Ortúzar, J., \& Rizzi, L. I. (2009). Estimating the willingness to pay and value of risk reduction for car occupants in the road environment. Transportation Research Part A: Policy and Practice, 43(7), 692-707.

Hess, S., \& Rose, J. M. (2009). Allowing for intra-respondent variations in coefficients estimated on repeated choice data. Transportation Research Part B: Methodological, 43(6), 708-719.

Ho, C. Q., \& Yamamoto, T. (2011). The role of attitudes and public transport service on vehicle 
ownership in Ho Chi Minh, Vietnam. 34th Australasian Transport Research Forum (ATRF), Adelaide, Australia, 28-30 September 2011.

Hole, A. R. (2007). A comparison of approaches to estimating confidence intervals for willingness to pay measures. Health Economics, 16(8), 827-840.

Hollander, Y. (2006). Direct versus indirect models for the effects of unreliability. Transportation Research Part A: Policy and Practice, 40(9), 699-711.

Hussain, A., Munn, I. A., Hudson, D., \& West, B. (2010). Attribute-based analysis of hunters' lease preferences. Journal of Environmental Management, 91(12), 2565-2571.

Jovicic, G., \& Hansen, C. O. (2003). A passenger travel demand model for Copenhagen. Transportation Research Part A: Policy and Practice, 37(4), 333-349.

Kjær, T. (2005). A review of the discrete choice experiment with emphasis on its application in health care. Health Economics, University of Southern Denmark, Odense, Denmark.

Lancaster, K. J. (1966). A new approach to consumer theory. Journal of Political Economy, 74(2), 132-157.

Lancsar, E., \& Louviere, J. (2008). Conducting discrete choice experiments to inform healthcare decision making. Pharmacoeconomics, 26(8), 661-677.

Leitham, S., McQuaid, R. W., \& Nelson, J. D. (2000). The influence of transport on industrial location choice: A stated preference experiment. Transportation Research Part A: Policy and Practice, 34(7), 515-535.

Li, C. Z., \& Mattsson, L. (1995). Discrete choice under preference uncertainty: An improved structural model for contingent valuation. Journal of Environmental Economics and Management, 28(2), 256-269.

Long, J. S., \& Freese, J. (2006). Regression models for categorical dependent variables using Stata. Stata press.

Manski, C. F. (1977). The structure of random utility models. Theory and Decision, 8(3), 229-254.

Marschak, J. (1959). Binary choice constraints on random utility indicators (No. 74). Cowles Foundation for Research in Economics, Yale University.

McDonnell, S., Ferreira, S., \& Convery, F. (2009). Bus priority provision and willingness to pay differentials resulting from modal choice and residential location: Evidence from a stated choice survey. Journal of Transport Economics and Policy, 43(2), 213-235.

McFadden, D., \& Train, K. (2000). Mixed MNL models for discrete response. Journal of Applied Econometrics, 15(5), 447-470.

McFadden, D. (1980). Econometric models for probabilistic choice among products. The Journal of Business, 53(3), S13-S29.

McFadden, D. (1986). The choice theory approach to market research. Marketing Science, 5(4), 275297.

McFadden, D. (2001). Economic choices. The American Economic Review, 91(3), 351-378.

McIntosh, E. (2006). Using discrete choice experiments within a cost-benefit analysis 
framework. Pharmacoeconomics, 24(9), 855-868.

Nguyen, K. P. (1999). Demand, supply, and pricing in urban road transport: The case of Ho Chi Minh City, Vietnam. Research in Transportation Economics, 5, 107-154.

Nguyen, A. T., Zhou, W., \& Yu, J. (2015). Study on influencing factors of residents' travel mode choice for Ho Chi Minh City. Journal of Science and Technology, 53(4), 503.

Puckett, S. M., \& Hensher, D. A. (2009). Revealing the extent of process heterogeneity in choice analysis: An empirical assessment. Transportation Research Part A: Policy and Practice, 43(2), $117-126$.

Puckett, S. M., Hensher, D. A., Rose, J. M., \& Collins, A. (2007). Design and development of a stated choice experiment for interdependent agents: Accounting for interactions between buyers and sellers of urban freight services. Transportation, 34(4), 429-451.

Rouwendal, J., de Blaeij, A., Rietveld, P., \& Verhoef, E. (2010). The information content of a stated choice experiment: A new method and its application to the value of a statistical life. Transportation Research Part B: Methodological, 44(1), 136-151.

Rungie, C. M., Coote, L. V., \& Louviere, J. J. (2011). Structural choice modelling: Theory and applications to combining choice experiments. Journal of Choice Modelling, 4(3), 1-29.

Sener, I. N., Eluru, N., \& Bhat, C. R. (2009). An analysis of bicycle route choice preferences in Texas, US. Transportation, 36(5), 511-539.

Thurstone, L. L. (1927). A law of comparative judgment. Psychological Review, 34(2), 273-286.

Train, K., \& Wilson, W. W. (2008). Estimation on stated-preference experiments constructed from revealed-preference choices. Transportation Research Part B: Methodological, 42(3), 191-203.

Train, K. E. (2009). Discrete choice methods with simulation. Cambridge University Press.

Tseng, Y. Y., \& Verhoef, E. T. (2008). Value of time by time of day: A stated-preference study. Transportation Research Part B: Methodological, 42(7), 607-618.

Tuong, N. T. C. (2014). Determinants of private mode choice in Ho Chi Minh City, Vietnam: From the individual perspective. World transport policy and practice, 20(1), 56-69.

Vu, T. T. A., \& Phuong, D. H. (2013). Combating traffic congestion in Hanoi and Ho Chi Minh City. Fulbright Economics Teaching Program.

Wang, B., Hensher, D. A., \& Ton, T. (2002). Safety in the road environment: A driver behavioural response perspective. Transportation, 29(3), 253-270.

Wang, D., Borgers, A., Oppewal, H., \& Timmermans, H. (2000). A stated choice approach to developing multi-faceted models of activity behavior. Transportation Research Part A: Policy and Practice, 34(8), 625-643.

Yang, L., Choudhury, C. F., Ben-Akiva, M., Abreu e Silva, J., \& Carvalho, D. (2009). Stated preference survey for new smart transport modes and services: Design, pilot study and new revision. Working Paper ITS-SCUSSE-09-02. Instituto Superior Tecnico, Lisbon, Portugal.

Zhang, J., Timmermans, H., Borgers, A., \& Wang, D. (2004). Modeling traveler choice behavior 
using the concepts of relative utility and relative interest. Transportation Research Part B:

Methodological, 38(3), 215-234.

\section{Appendix}

\begin{tabular}{|c|c|c|c|c|c|c|c|c|}
\hline Price & No seat available & Seat available & Price & No seat available & Seat available & Price & No seat available & Seat available \\
\hline 0 & 0.732891071 & 0.791590968 & 1900 & 0.30205362 & 0.371415103 & 3800 & 0.0894866177 & 0.117284621 \\
\hline 50 & 0.723307742 & 0.783545967 & 1950 & 0.292811369 & 0.361000657 & 3850 & 0.086715414 & 0.113761828 \\
\hline 100 & 0.713458845 & 0.775227204 & 2000 & 0.283804079 & 0.350795611 & 3900 & 0.084036967 & 0.110350776 \\
\hline 150 & 0.703349012 & 0.766633209 & 2050 & 0.27503147 & 0.340804077 & 3950 & 0.08144772 & 0.107048032 \\
\hline 200 & 0.692984375 & 0.757763609 & 2100 & 0.266492611 & 0.331029263 & 4000 & 0.078944648 & 0.103850243 \\
\hline 250 & 0.682372621 & 0.748619242 & 2150 & 0.258185986 & 0.321473526 & 4050 & 0.076524822 & 0.100754135 \\
\hline 300 & 0.671523035 & 0.73920225 & 2200 & 0.250109556 & 0.312138445 & 4100 & 0.074185398 & 0.097756517 \\
\hline 350 & 0.660446511 & 0.729516182 & 2250 & 0.242260818 & 0.303024873 & 4150 & 0.071923624 & 0.094854278 \\
\hline 400 & 0.649155548 & 0.719566061 & 2300 & 0.234636862 & 0.294133006 & 4200 & 0.069736835 & 0.092044389 \\
\hline 450 & 0.637664204 & 0.709358457 & 2350 & 0.227234423 & 0.285462437 & 4250 & 0.06762245 & 0.089323899 \\
\hline 500 & 0.625988036 & 0.698901525 & 2400 & 0.220049927 & 0.277012215 & 4300 & 0.065577973 & 0.086689942 \\
\hline 550 & 0.614143998 & 0.688205023 & 2450 & 0.213079541 & 0.268780899 & 4350 & 0.063600988 & 0.084139726 \\
\hline 600 & 0.602150321 & 0.677280312 & 2500 & 0.206319211 & 0.260766612 & 4400 & 0.06168916 & 0.081670542 \\
\hline 650 & 0.590026358 & 0.666140317 & 2550 & 0.199764697 & 0.252967088 & 4450 & 0.059840231 & 0.079279756 \\
\hline 700 & 0.577792414 & 0.654799468 & 2600 & 0.193411615 & 0.245379718 & 4500 & 0.058052019 & 0.076964812 \\
\hline 750 & 0.565469548 & 0.643273609 & 2650 & 0.187255461 & 0.238001594 & 4550 & 0.056322416 & 0.07472323 \\
\hline 800 & 0.553079372 & 0.631579879 & 2700 & 0.181291641 & 0.230829546 & 4600 & 0.054649384 & 0.072552603 \\
\hline 850 & 0.540643831 & 0.61973657 & 2750 & 0.175515499 & 0.223860181 & 4650 & 0.053030958 & 0.070450597 \\
\hline 900 & 0.528184984 & 0.607762964 & 2800 & 0.169922335 & 0.217089917 & 4700 & 0.051465239 & 0.068414953 \\
\hline 950 & 0.515724793 & 0.595679143 & 2850 & 0.164507429 & 0.210515012 & 4750 & 0.049950393 & 0.066443476 \\
\hline 1000 & 0.503284909 & 0.583505799 & 2900 & 0.159266056 & 0.20413159 & 4800 & 0.048484651 & 0.064534045 \\
\hline 1050 & 0.490886484 & 0.571264025 & 2950 & 0.154193505 & 0.197935673 & 4850 & 0.047066306 & 0.062684605 \\
\hline 1100 & 0.4785499855 & 0.558975111 & 3000 & 0.14928509 & 0.191923196 & 4900 & 0.04569371 & 0.060893164 \\
\hline 1150 & 0.46629504 & 0.546660334 & 3050 & 0.144536162 & 0.186090034 & 4950 & 0.044365275 & 0.059157796 \\
\hline 1200 & 0.454140301 & 0.534340767 & 3100 & 0.139942121 & 0.180432017 & 5000 & 0.043079467 & 0.057476639 \\
\hline 1250 & 0.44210333 & 0.522037085 & 3150 & 0.135498424 & 0.174944948 & 5050 & 0.041834808 & 0.055847889 \\
\hline 1300 & 0.430200509 & 0.509769402 & 3200 & 0.131200597 & 0.169624617 & 5100 & 0.040629872 & 0.054269802 \\
\hline 1350 & 0.418446978 & 0.497557116 & 3250 & 0.127044233 & 0.164466815 & 5150 & 0.039463284 & 0.052740693 \\
\hline 1400 & 0.406856584 & 0.485418774 & 3300 & 0.123025005 & 0.159467348 & 5200 & 0.038333719 & 0.051258932 \\
\hline 1450 & 0.395441865 & 0.473371963 & 3350 & 0.119138671 & 0.154622043 & 5250 & 0.037239898 & 0.049822943 \\
\hline 1500 & 0.384214043 & 0.461433221 & 3400 & 0.115381071 & 0.149926759 & 5300 & 0.036180591 & 0.048431205 \\
\hline 1550 & 0.373183034 & 0.449617967 & 3450 & 0.111748137 & 0.145377396 & 5350 & 0.035154608 & 0.047082245 \\
\hline
\end{tabular}




\begin{tabular}{lll|lll|lll}
1600 & 0.36235748 & 0.437940455 & 3500 & 0.108235892 & 0.140969902 & 5400 & 0.034160804 & 0.045774643 \\
1650 & 0.351744787 & 0.42641374 & 3550 & 0.104840455 & 0.136700279 & 5450 & 0.033198078 & 0.044507026 \\
1700 & 0.341351172 & 0.415049671 & 3600 & 0.101558037 & 0.132564585 & 5500 & 0.032265364 & 0.043278067 \\
1750 & 0.331181721 & 0.403858893 & 3650 & 0.098384946 & 0.128558947 & 5550 & 0.031361637 & 0.042086486 \\
1800 & 0.321240455 & 0.39285086 & 3700 & 0.095317589 & 0.124679553 & 5600 & 0.03048591 & 0.040931047 \\
1850 & 0.311530391 & 0.382033872 & 3750 & 0.092352467 & 0.120922666 & & & \\
\hline
\end{tabular}

